\title{
Hydrothermal Preparation of Phyllostachys pubescens - nanocellulose/Graphene Aerogel as a Simple Device for Supercapacitors
}

\author{
Yan-Yun Wang, Qing-Jin Fu, Xiao Ning, Ge-Gu Chen, and Chun-Li Yao * \\ Bamboo nanocellulose can be regarded as a promising biomass material \\ for the preparation of sustainable energy devices due to its unique \\ structure, excellent properties, and wide range of sources. A highly \\ conductive electrochemical energy storage was synthesized due to the \\ excellent electrical conductivity of graphene and the high surface area of \\ nanocellulose and graphene, which was beneficial for producing a \\ network structure. The symmetric capacitor assembled from the \\ Phyllostachys pubescens nanocellulose/graphene aerogel (CGA) \\ electrode exhibited a high specific capacitance of $125.5 \mathrm{~F} / \mathrm{g}$ at $5 \mathrm{mV} / \mathrm{s}$ \\ and extreme stability of $98.3 \%$ capacitance retention ratio after 5000 \\ cycles at $2 \mathrm{~A} / \mathrm{g}$. This nanocellulose-graphene electrode showed potential \\ for future high-performance supercapacitors.
}

Keywords: Nanocellulose; Sustainables; Supercapacitors; Graphene oxide; Aerogel

Contact information: Beijing Key Laboratory of Lignocellulosic Chemistry, Beijing Forestry University, Beijing 100083, China; *Corresponding author: chunliyao2006@163.com

\section{INTRODUCTION}

Supercapacitors, as electrochemical capacitors, can be regarded as the most promising energy storage devices. They have received increased attention because of their high power density, high charging/discharging rate capability, excellent reversibility, and long cycling life (Lei et al. 2016). Supercapacitors can be classified into electrochemical double-layer capacitors (EDLC) and pseudocapacitors based on different charge mechanisms. The capacitance of EDLCs relies on electrostatic charge diffusion and adsorption between the surface of the electrode and electrolyte solution (González et al. 2016). Carbon materials, such as activated graphene (Zhu et al. 2011), carbon nanotubes (CNTs) (Izadi - Najafabadi et al. 2010), mesoporous carbons (Sun et al. 2012), and carbide-derived carbons (Merlet et al. 2012), as a kind of EDLC electrode material, can provide efficient charge separation in electrolyte solutions and enhance the overall electron transport efficiency in the electrode (Li et al. 2016). In recent years, there has been an increasing interest in combining two carbon materials, such as graphene and activated carbons (ACs) (Xu et al. 2015; Yu et al. 2014), graphene and CNTs (Saeed et al. 2018), or carbon nanofibers and ACs (Gryglewicz et al. 2013), to improve the electrochemical properties of materials. However, the composites with two carbon materials usually do not achieve the desired results because of the lack of affinity between the different carbon materials, which results in a poor distribution and aggregation of the same material (Du et al. 2017).

Cellulose is the most abundant renewable natural polysaccharide (Titirici et al. 2012). Nanocellulose derived from cellulose is one of the most promising sustainable 
nanomaterials (Dufresne 2013). Nanocellulose has a high aspect ratio, excellent mechanical properties, impressive flexibility, and excellent hydrophilicity, making it easy to assemble carbon materials into flexible, adhesive-free, and high-performance electrodes (Okita et al. 2010; Saito et al. 2006). Wang et al. (2013) prepared a coresheath conductive nanocomposite with excellent conductivity of $77 \mathrm{~S} \cdot \mathrm{cm}^{-1}$ (Zhang et al. 2019). Wu et al. (2014) developed a core-shell PPy / PVP / CNC conductive material with high conductivity of $36.9 \mathrm{~S} \cdot \mathrm{cm}^{-1}$ and excellent specific capacitance of $322.6 \mathrm{~F} \cdot \mathrm{g}^{-1}$, and improved cycle stability. Zhou et al. (2013) used graphite nanosheets (GNPs) to insert bacterial cellulose (BC) to increase the electrical conductivity of the composite membrane and obtain a maximum conductivity of $1.2 \mathrm{~S} \cdot \mathrm{m}^{-1}$. Feng et al. (2012) proposed a highly flexible nanocomposite film of bacterial cellulose (BC) and graphene oxide (GO) with flexible structure by vacuum assisted self-assembly technology. The conductivity of the composite film containing $1 \mathrm{wt} \% \mathrm{GO}$ after in situ reduction showed a significant increase of 6 orders of magnitude compared with the insulated BC. Park et al. (2016) prepared a unique conductive bacterial cellulose (BC) composite with silicon nanoparticles (SiNPs) and polyaniline, which achieved very stable electrical conductivity even after repeated bending for more than 100 times. Furthermore, nanocellulose possesses a hydroxyl-containing reactive surface that can be beneficial for the contact between the electrodes and electrolytes as well as to enhance the electrochemical performance of the electrodes (Chen et al. 2018).

In this work, the authors prepared nanocellulose from Phyllostachys pubescens as a raw material, and a lightweight porous flexible supercapacitor (nanocellulose/graphene aerogel, CGA) based on nanocellulose and graphene oxide was prepared by a green hydrothermal method. In the graphene-nanocellulose aerogel electrode, nanocellulose can effectively avoid the aggregation between graphene sheets and form a stable 3D network structure with graphene oxide, which not only enhances the flexibility of the composite electrode, but also solves the ion diffusion problem caused by the aggregation of graphene sheets (Gao et al. 2013). In particular, two important factors, the reaction temperature and the ratio of nanocellulose to graphene, were suitably optimized. The prepared CGA exhibits a good diffusion channel, a rich reaction site for electrostatic attraction and molecular migration, and allows electrolyte ions to be continuously and stably transported to the surface, which leads to an excellent electrochemical performance. The CGA not only has extensive application prospects in flexible energy devices, such as supercapacitors, but also improves the high value application of bamboo cellulose.

\section{EXPERIMENTAL}

\section{Materials}

Preparation of graphene oxide (GO)

The GO was prepared by a chemical treatment of exfoliated natural graphite powders (Qingdao Chenglong Graphite Co., Ltd., Qingdao, China) according to the modified method of Hummers, Jr. and Offeman (Hummers Jr and Offeman 1958). The final concentration of $\mathrm{GO}$ dispersion was $6.3 \mathrm{mg} / \mathrm{mL}$. The GO dispersion was further diluted to $2 \mathrm{mg} / \mathrm{mL}$ by adding deionized water. 


\section{Preparation of cellulose nanofibers (CNFs)}

The cellulose extraction and purification of Phyllostachys pubescens and CNF preparation methods were referred to in the literature (Chen et al. 2011; Isogai et al. 2011). First, the bamboo powder was subjected to solvent extraction with a toluene/ethanol (2:1) (toluene, Fortuneibo-Tech Co., Ltd., Shanghai, China; ethanol, Fujian Zhonghe Environmental Protection Technology Co., Ltd., Fujian, China) mixture for $6 \mathrm{~h}$. Next, the sample was subjected to delignification treatment at $75^{\circ} \mathrm{C}$ for $1 \mathrm{~h}$ with an acidified sodium chlorite solution (Jinan Huijinchuan Trading Co., Ltd., Shandong, China), and the process was repeated seven times. Then, the sample was treated with 2 wt\% potassium hydroxide (Zhengzhou Shuangchen Trading Co., Ltd., Henan, China) at $90{ }^{\circ} \mathrm{C}$ for $2 \mathrm{~h}$ to remove hemicellulose and obtain highly purified cellulose. Finally, it was treated with a 1 wt\% hydrochloric acid solution (Jining Huicheng Huagong Co., Ltd., Shandong, China) at $80^{\circ} \mathrm{C}$ for $2 \mathrm{~h}$ to obtain cellulose fibers.

The above cellulose fibers $(2 \mathrm{~g})$ were suspended in a solution $(200 \mathrm{~mL})$ that contained 2,2,6,6-tetramethylpiperidine-N-oxyl (TEMPO) (0.032 g) (Guangzhou Hu'ao Chemical Co., Ltd., Guangdong, China) and sodium bromide (0.2 g) (He'nan Dingjing Chemical Products Co., Ltd., He'nan, China). The cellulose fibers were oxidized by adding the $\mathrm{NaClO}$ solution (10 mmol/g cellulose) (Jinan Huijinchuan Trading Co., Ltd., Shandong, China) for $6 \mathrm{~h}$. The $\mathrm{pH}$ of the reaction solution was maintained at 10 by adding $0.5 \mathrm{M} \mathrm{NaOH}$ (Jiaxiang Sea Chemical Co., Ltd., Shandong, China) during the reaction at $10{ }^{\circ} \mathrm{C}$. The $1 \mathrm{wt} \%$ oxidized cellulose/water slurries were ultrasonicated for 30 min at a power of $500 \mathrm{~W}$ in an ice bath. Finally, the sample was washed with distilled water to a neutral $\mathrm{pH}$ and stored at $4{ }^{\circ} \mathrm{C}$.

\section{Preparation of $C G A$}

The GO (2 mg/mL, $15 \mathrm{~mL})$ and CNF slurry (3 g, $1 \mathrm{wt} \%)$ were uniformly mixed with ultrasonication for $60 \mathrm{~min}$. Subsequently, the mixture was transferred to a Teflonlined autoclave and heated at $180{ }^{\circ} \mathrm{C}$ for $12 \mathrm{~h}$ to synthesize a cellulose nanofiber/graphene hydrogel $(\mathrm{CGH})$. Finally, a cellulose nanofiber/graphene aerogel was obtained after freeze-drying and carbonization, and was named as CGA-1:1 (CGA-180 ${ }^{\circ} \mathrm{C}$ ). The preparation conditions of each aerogel are shown in Table 1. For comparison, graphene aerogel (GA) was prepared directly from GO. The GO $(2 \mathrm{mg} / \mathrm{mL}, 15 \mathrm{~mL})$ was transferred to a Teflon-lined autoclave and heated at $180{ }^{\circ} \mathrm{C}$ for $12 \mathrm{~h}$ to synthesize the graphene hydrogel. Finally, the graphene aerogel was obtained after freeze-drying and carbonization, and was named as GA.

Table 1. Preparation of Aerogels at Different Temperatures and Ratios

\begin{tabular}{|c|c|c|}
\hline & Temperature $\left({ }^{\circ} \mathrm{C}\right)$ & Ratio of CNF and GO \\
\hline $\mathrm{CGA}-120^{\circ} \mathrm{C}$ & 120 & \multirow{4}{*}{$1: 1$} \\
\hline CGA $-150^{\circ} \mathrm{C}$ & 150 & \\
\hline $\mathrm{CGA}-180^{\circ} \mathrm{C}$ & 180 & \\
\hline $\mathrm{CGA}-210^{\circ} \mathrm{C}$ & 210 & \\
\hline GA & \multirow{4}{*}{180} & $0: 1$ \\
\hline CGA-1:2 & & $1: 2$ \\
\hline CGA-1:1 & & $1: 1$ \\
\hline CGA-2:1 & & $2: 1$ \\
\hline
\end{tabular}

Wang et al. (2020). "Nanocellulose/graphene aerogel," BioResources 15(1), 677-690. 


\section{Methods}

A Nanoscope IIIa atomic force microscope (Veeco Instruments Inc., Plainview, NY, USA) was used to characterize the morphology and size images of graphene oxide and nanocellulose. In the sample preparation, a drop of the diluted graphene oxide or cellulose solution was dispersed on the surface of an optical glass substrate, allowed to dry at ambient temperature, and then analyzed. The microstructure and morphology of samples were observed with a scanning electron microscope (SEM, Hitachi S-4800; Hitachi, Tokyo, Japan). X-ray diffraction (XRD) patterns were measured on an Ultima IV multipurpose X-ray diffraction system (Rigaku, Tokyo, Japan) with $\mathrm{CuK} \alpha$ radiation (40 $\mathrm{kV}$ and $30 \mathrm{~mA}$ ) at a scanning rate of $5 \% \mathrm{~min}$. Nitrogen adsorption-desorption isotherm measurements were performed using a 3H-2000PS2 Brunauer-Emmett-Teller (BET) surface area analyzer (Yima Optoelec Co., Ltd, Xi'an, China). The pore size distribution of samples was estimated by the Barret-Joyner-Halenda (BJH) method.

\section{Electrochemical Measurements}

The electrochemical performances were evaluated by a CHI760e electrochemical workstation (Shanghai Chenhua Instrument Co., Ltd., Shanghai, China) using a twoelectrode system in $1 \mathrm{M} \mathrm{H}_{2} \mathrm{SO}_{4}$ electrolyte solution. The prepared aerogels were cut into pieces with a thickness of $2 \mathrm{~mm}$ and directly used as the working electrode. Cyclic voltammetry $(\mathrm{CV})$ measurements were recorded over the potential range of $0 \mathrm{~V}$ to $1 \mathrm{~V}$ at different scan rates ranging from $5 \mathrm{mV} / \mathrm{s}$ to $100 \mathrm{mV} / \mathrm{s}$. Galvanostatic charge-discharge (GCD) tests were conducted in the potential range of $0 \mathrm{~V}$ to $1 \mathrm{~V}$ at current densities of $0.2 \mathrm{~A} / \mathrm{g}, 0.3 \mathrm{~A} / \mathrm{g}, 0.5 \mathrm{~A} / \mathrm{g}, 1 \mathrm{~A} / \mathrm{g}$, and $2 \mathrm{~A} / \mathrm{g}$. Electrochemical impedance spectroscopy (EIS) curves were detected at a frequency range of $10 \mathrm{mHz}$ to $100 \mathrm{KHz}$ and the oscillation potential amplitude of $10 \mathrm{mV}$. Moreover, the specific capacitance $\left(C_{\mathrm{s}}\right)$ was calculated based on the CV curves according to the following equation (Wen et al. 2016),

$$
C_{s}=\frac{\int I(V) \mathrm{d} V}{\mathrm{~m} v \Delta V}
$$

where $I$ is the current density applied (A), $\Delta V$ is the applied voltage $(\mathrm{V}), v$ is the scan rate $(\mathrm{mV} / \mathrm{s})$, and $m$ is the mass of the electroactive material in the working electrode $(\mathrm{g})$.

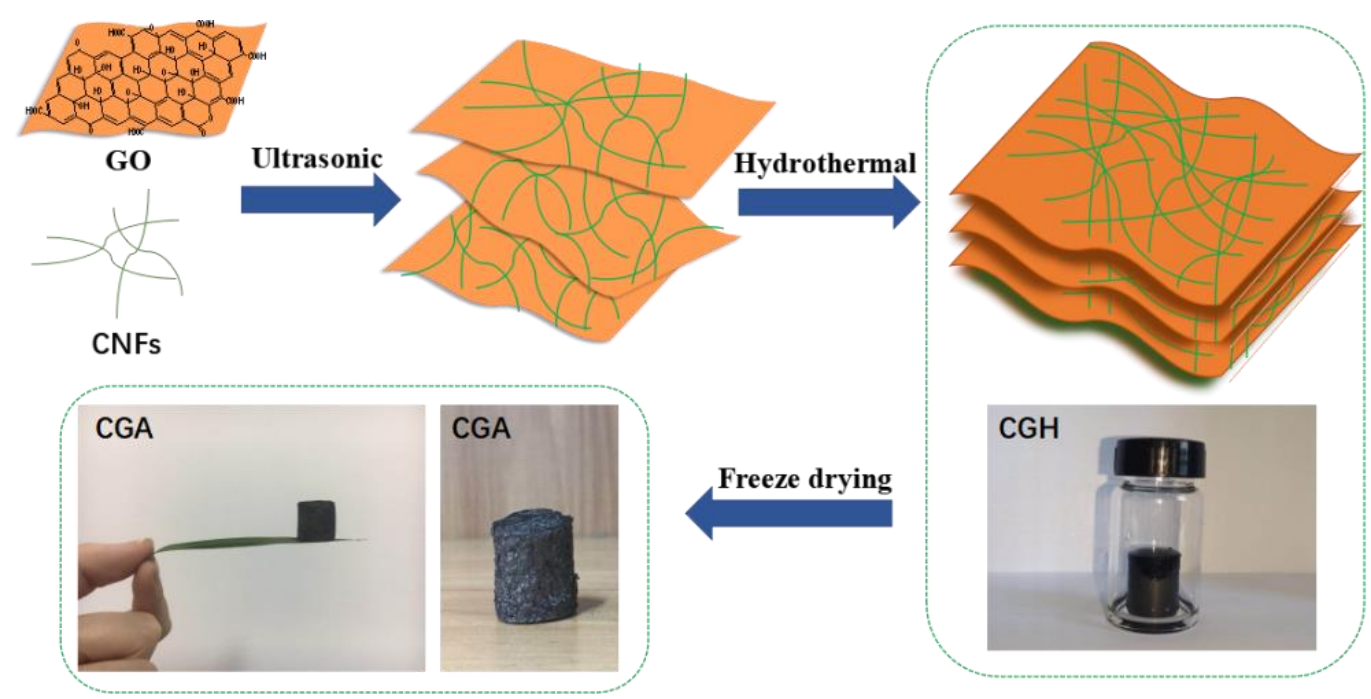

Fig. 1. Schematic illustration of the formation process of CGA 


\section{RESULTS AND DISCUSSION}

\section{Characterizations}

Figures $2 \mathrm{a}$ and $2 \mathrm{~b}$ are atomic force micrographs (AFM) of GO and CNF, respectively. Figure $2 \mathrm{a}$ shows that the graphene oxide was uniformly dispersed in the liquid, and the thickness of the single-layer GO was measured as $1.28 \mathrm{~nm}$. Figure $1 \mathrm{~b}$ shows that the CNF prepared by the TEMPO oxidation method had an interlaced network structure, and the width of the single elongated fiber was approximately $2 \mathrm{~nm}$ to $3 \mathrm{~nm}$.
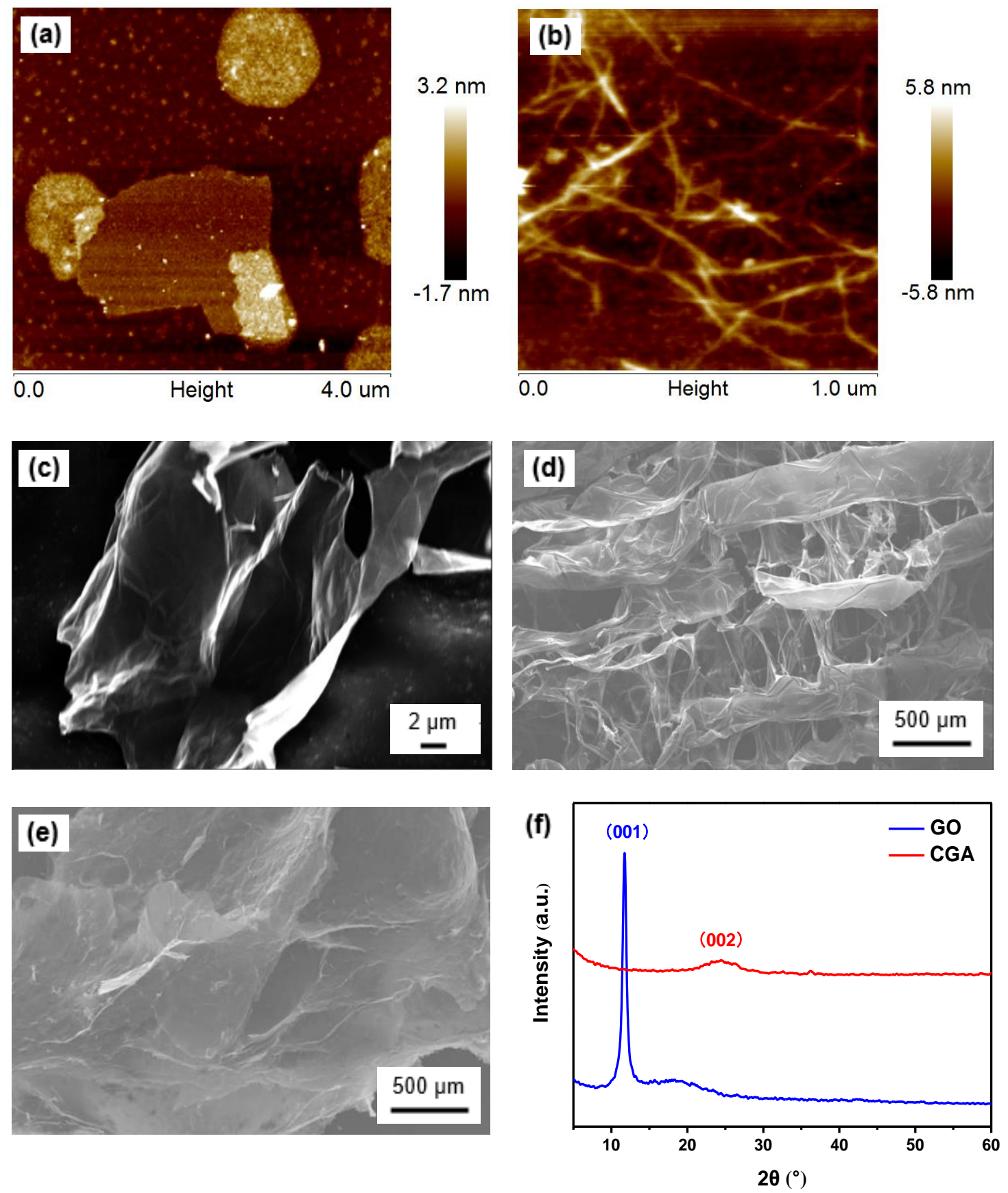

Fig. 2. AFM images of (a) GO and (b) CNFs; SEM images of (c) GO, (d) CNF aerogel, and (e) CGA; (f) XRD of GO and CGA 
Figures 1c to 1e show the morphology and microstructure of GO, CNF aerogel, and CGA through the SEM. Figure 2c shows a thin single layer of GO sheet and a smooth surface (Hao et al. 2015). The CNF aerogel in Fig. 2d shows a 3D network-like nanostructure and many interconnected pores. The SEM image of the CGA composite electrode (Fig. 2e) shows that CNF and GO crosslinked to form a layered, interconnected porous structure with an ultra-high porosity that facilitated the electrolyte entering the interior of the electrode during the electrochemical reaction. In this process, CNF helped to reduce the aggregation of graphene sheets and bridged GO to form a cross-linked 3D loose structure, thereby promoting the rapid diffusion of electrolyte ions (Suktha et al. 2015). Figure 1f shows the typical XRD patterns of GO and CGA, which demonstrated the structural differences between the two samples. Figure 1f shows that the peak in the GO pattern at $2 \theta=11.83^{\circ}$ corresponded to the characteristic peak (001) reflection of GO. And the CGA composite only showed a broad and low-intensity diffraction peak at $2 \theta=$ $24.54^{\circ}$, which corresponded to the (002) diffraction peak of graphene, indicating that GO has been converted into graphene by hydrothermal treatment (Sui et al. 2015).

\section{Table 2. Pore Structure Characteristics}

\begin{tabular}{|c|c|c|c|}
\hline Sample ID & $S_{\mathrm{BET}}\left(\mathrm{m}^{2} / \mathrm{g}\right)$ & $V_{\text {tot }}\left(\mathrm{m}^{3} / \mathrm{g}\right)$ & $W_{\mathrm{p}}(\mathrm{nm})$ \\
\hline $\mathrm{GA}$ & 25.00 & 0.11 & 18.35 \\
\hline CNF & 8.56 & 0.04 & 19.86 \\
\hline CGA & 17.71 & 0.08 & 17.93 \\
\hline \multicolumn{4}{|l|}{$\begin{array}{l}S_{\mathrm{BET}} \text { is the specific surface area, } V_{\text {tot }} \text { is the total pore volume }\left(P / P_{0}=0.99768871, \text { pore }\right. \\
\text { diameter }<832.8 \mathrm{~nm}), \text { and } W_{\mathrm{p}} \text { is the adsorption average pore size. }\end{array}$} \\
\hline
\end{tabular}

Figure 3 shows the pore size distribution and nitrogen isotherm adsorption curves obtained by the BJH method. Figure 2 shows that the pore sizes of GA, CNF aerogel, and CGA were mainly distributed at $2 \mathrm{~nm}$ to $10 \mathrm{~nm}$, which indicated that there were mesopores in these three samples, but there were no micropores detected. The maximum pore diameters of GA, CNF, and CGA were $3.15 \mathrm{~nm}, 2.93 \mathrm{~nm}$, and $3.61 \mathrm{~nm}$, respectively. Table 2 shows the pore structure characteristics of GA, CNF aerogel, and CGA. Table 2 shows that the specific surface areas of the GA, CNF aerogel, and CGA electrode were $25.00 \mathrm{~m}^{2} / \mathrm{g}, 8.56 \mathrm{~m}^{2} / \mathrm{g}$, and $17.71 \mathrm{~m}^{2} / \mathrm{g}$, respectively.

As can be seen from Fig. 3, the pore size distribution of GA was the most uneven, which can be attributed to the agglomeration of graphene. Therefore, although the specific surface area of GA was relatively high, the uneven dispersion problem of the internal pore size was not conducive to the diffusion of electrolyte ions, which may affect its electrochemical performance. However, compared with GA, the pore size distribution of CGA was more uniform, indicating that CNF as a skeleton, which plays a good supporting role, avoided the aggregation of graphene sheets and forms a good threedimensional network structure, which was beneficial to the cycle performance of the electrode. At the same time, $\mathrm{CNF}$ has good hydrophilicity, which helps to absorb electrolyte ions and provides an effective ion transport route, which is beneficial to the specific capacitance of CGA electrodes. 

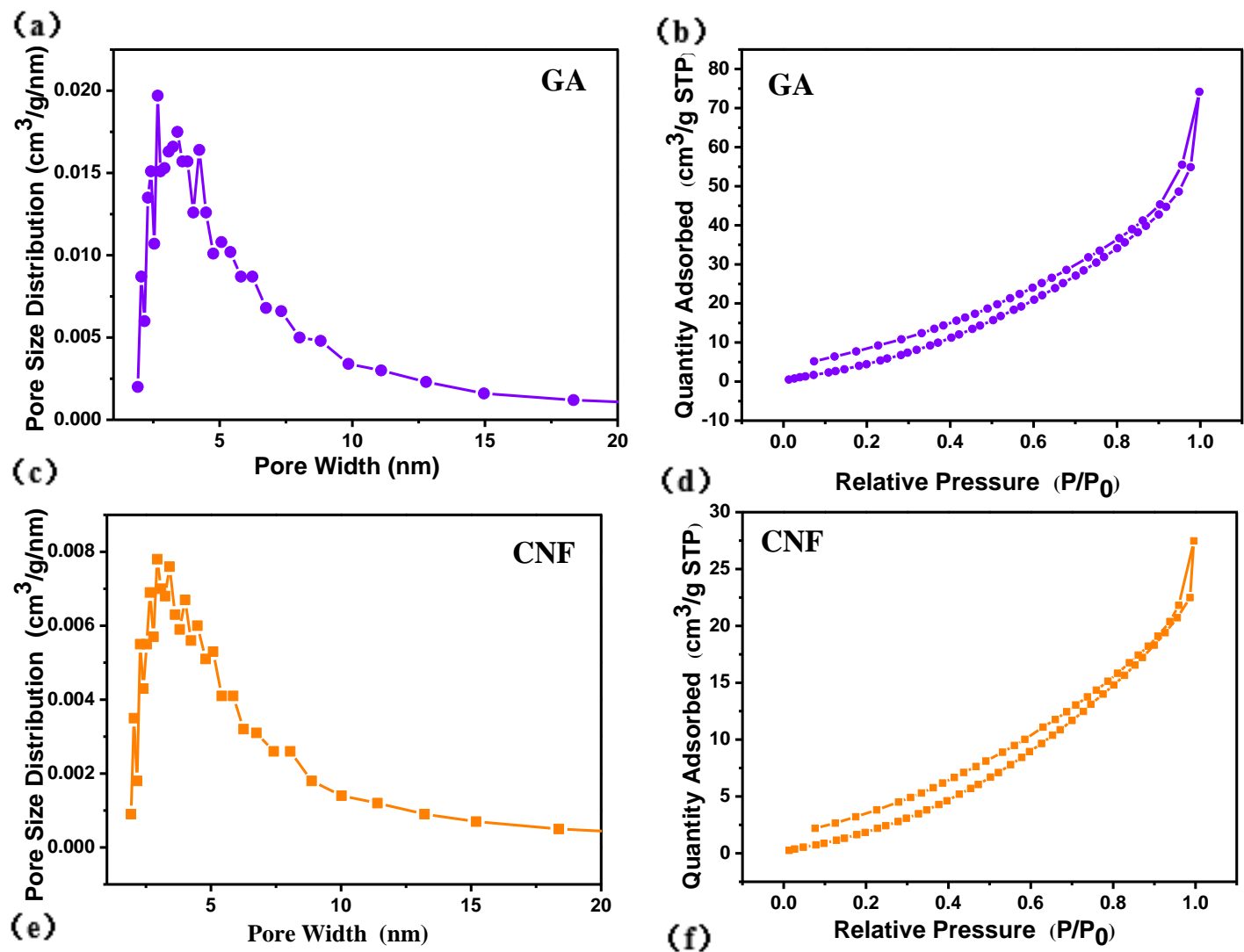

(d)
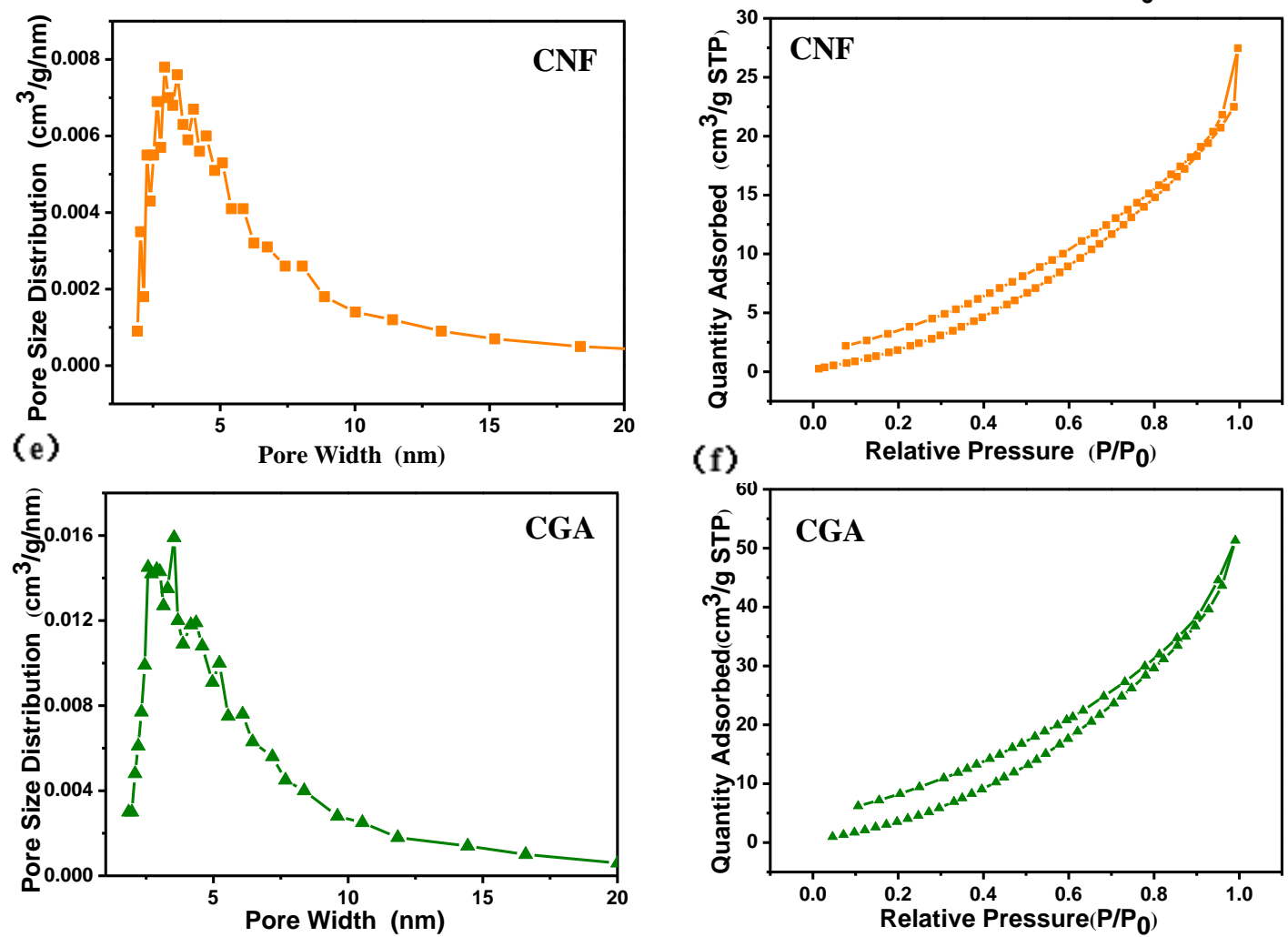

Fig. 3. Pore size distribution of (a) GA, (c) CNF, and (e) CGA; the nitrogen adsorption/desorption isotherms of (b) GA, (d) CNF, and (f) CGA

\section{Electrochemical Performances of CGA Electrodes at Different Temperatures and Ratios}

In a two-electrode system, cyclic voltammetry (CV), constant current charge and discharge (GCD), and electrochemical impedance spectroscopy (EIS) were performed on the symmetric capacitor assembled from these electrodes to investigate the effect of electrochemical performances of CGA electrodes at different temperatures (Figs. 4a to 4c) and ratios (Figs. 4d to 4f). The aerogel electrodes prepared under different temperature conditions were recorded as CGA-120 ${ }^{\circ} \mathrm{C}$, CGA-150 ${ }^{\circ} \mathrm{C}$, CGA-180 ${ }^{\circ} \mathrm{C}$, and CGA-210 ${ }^{\circ} \mathrm{C}$. Similarly, as-prepared aerogel electrodes were recorded as GA, CGA-1:2, CGA-1:1, and CGA-2:1 according to the mass ratio of nanocellulose and graphene. 

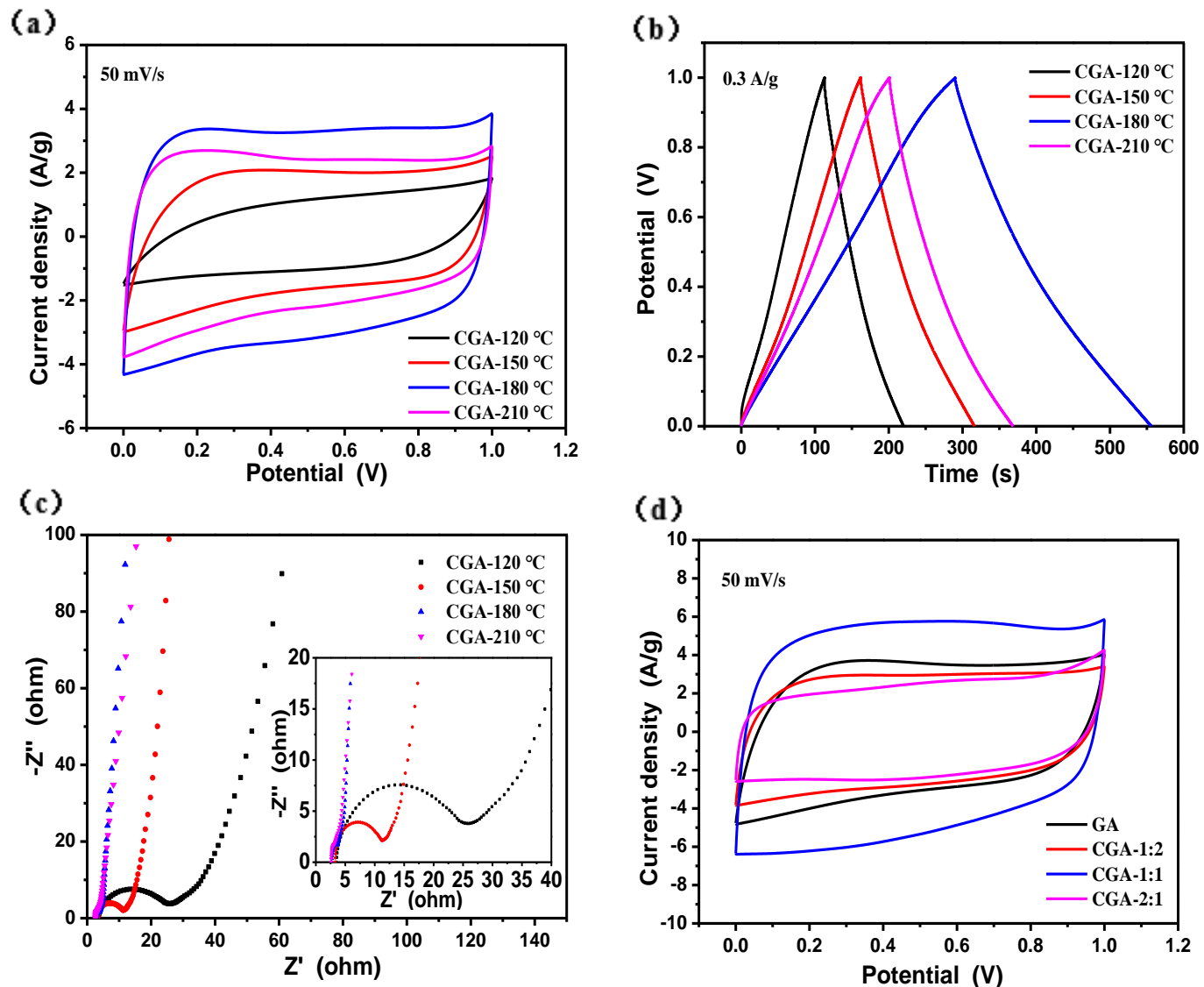

(e)
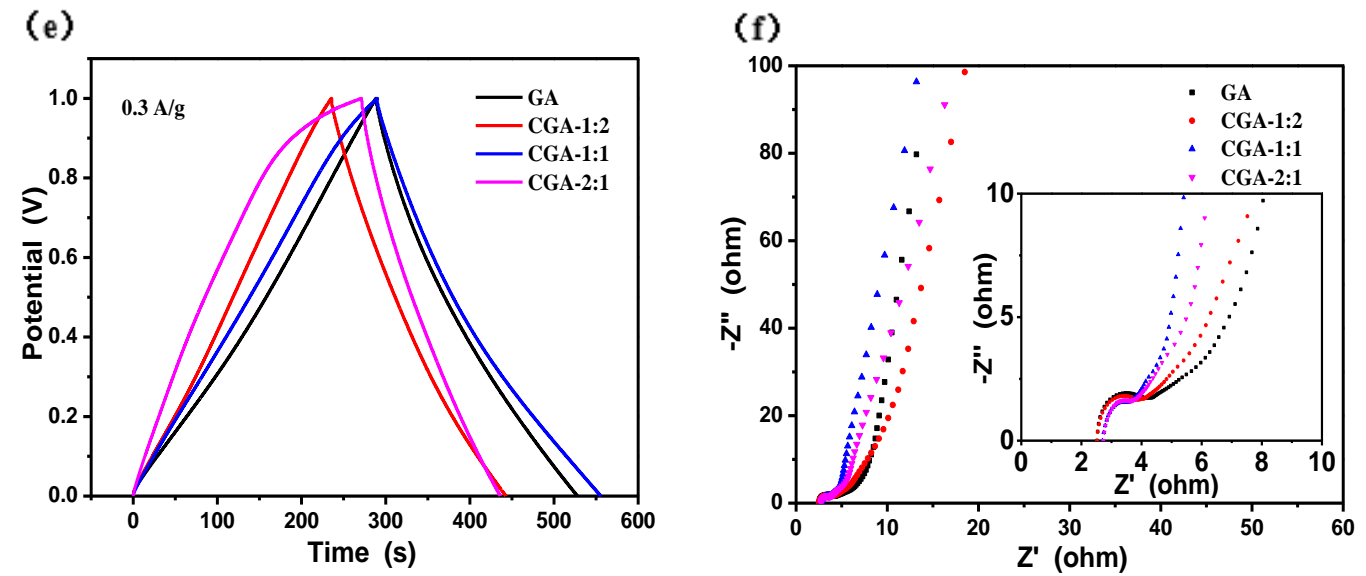

Fig. 4. CGA electrodes at different temperatures: (a) CV curves measured at the scan rate of 50 $\mathrm{mV} / \mathrm{s}$, (b) the GCD curves at a current density of $0.3 \mathrm{~A} / \mathrm{g}$, (c) Nyquist plots, inset shows the magnified high-frequency regions; CGA electrodes at different ratios: (d) CV curves measured at the scan rate of $50 \mathrm{mV} / \mathrm{s}$, (e) the GCD curves at a current density of $0.3 \mathrm{~A} / \mathrm{g}$, and (f) Nyquist plots, inset shows the magnified high-frequency regions

Figure $4 \mathrm{a}$ shows the $\mathrm{CV}$ curves of CGA electrodes prepared under different temperatures at a scan rate of $50 \mathrm{mV} / \mathrm{s}$. The $\mathrm{CV}$ curves of CGA- $120{ }^{\circ} \mathrm{C}, \mathrm{CGA}-150{ }^{\circ} \mathrm{C}$, CGA-180 ${ }^{\circ} \mathrm{C}$, and CGA-210 ${ }^{\circ} \mathrm{C}$ showed nearly rectangular shape, which indicated the ideal electric double layer capacitance (EDLC) behavior of the samples (Yan et al. 2014). Notably, CGA- $180{ }^{\circ} \mathrm{C}$ had the largest integrated area of the $\mathrm{CV}$ curve, which meant that CGA $-180^{\circ} \mathrm{C}$ had a better capacitance performance than the other three CGA electrodes. 
The GCD curve of the CGA electrodes prepared under different temperatures was measured at the current density of $0.3 \mathrm{~A} / \mathrm{g}$ (Fig. 4b). All GCD curves exhibited a shape close to the ideal isosceles triangle without a noticeable voltage drop (IR), which indicated that these CGA electrodes had excellent capacitance performance. The CGA$180{ }^{\circ} \mathrm{C}$ had the longest time to complete a charge-discharge process, which indicated that $180{ }^{\circ} \mathrm{C}$ was the most suitable temperature for preparing CGA electrodes.

The Nyquist plot in Figure 4c was used to analyze the electrochemical transfer properties of the CGA electrodes. The equivalent series resistance (ESR) of CGA- $180{ }^{\circ} \mathrm{C}$ $(3.1 \Omega)$ was smaller than other CGA electrodes, showing better capacitive characteristics than other CGA electrodes. The Nyquist plot was close to a semi-arc shape in the high frequency region, which showed the charge transfer process at the interface between the active ingredient and the electrolyte. The semicircle of CGA-180 ${ }^{\circ} \mathrm{C}$ in the high frequency region was the smallest, which indicated that the charge transfer resistance $\left(R_{\mathrm{ct}}\right)$ was the lowest. Similarly, Fig. 4c clearly shows that the Nyquist plot of CGA-180 ${ }^{\circ} \mathrm{C}$ at the low frequency region was the most vertical, which indicated that the CGA-180 ${ }^{\circ} \mathrm{C}$ had better capacitive characteristics than other CGA electrodes.

Figure $4 \mathrm{~d}$ shows the CV curves of the GA, CGA-1:2, CGA-1:1, and CGA-2:1 electrodes at a scan rate of $50 \mathrm{mV} / \mathrm{s}$. The CGA-1:1 curve shape was closer to a big rectangle than the CGA-1:2, CGA-2:1, and GA, which was an ideal electrical double layer capacitor. Figure 4e shows the GCD curve of the CGA electrode at a current density of $0.3 \mathrm{~A} / \mathrm{g}$. The GCD curves of GA, CGA-2:1, CGA-1:1, and CGA-1:2 were linear, exhibiting a typical triangle, which indicated good electrochemical capacitance characteristics. The CGA-1:1 electrode needed the longest time to complete a chargedischarge cycle. Among these electrodes, the Nyquist curve (Fig. 4f) of the CGA1:1 electrode exhibited a minimum semicircle diameter in the high frequency region, indicating that the charge transfer resistance $\left(R_{\mathrm{ct}}\right)$ was the lowest, and the curve in the low frequency region was the most perpendicular to the $Z$ axis, indicating good ion diffusion rate and excellent adsorption performance on the electrode surface.

\section{Electrochemical Performances of CGA Electrode}

Figure 5a shows that the rectangular area of the CGA (prepared under the temperature of $180{ }^{\circ} \mathrm{C}$ and $1: 1$ ratio of GO and CNF) increased with increasing scan rate from $5 \mathrm{mV} / \mathrm{s}$ to $100 \mathrm{mV} / \mathrm{s}$ in $1 \mathrm{M} \mathrm{H}_{2} \mathrm{SO}_{4}$ electrolyte, which indicated that CGA electrode had a good rate performance (Du et al. 2014). All of the GCD curves at different current densities are shown in Fig. 5b. All curves had a nearly linear slope and an almost symmetrical isosceles triangle shape, which indicated a fast current-voltage response and high power transfer efficiency of the CGA electrode (Jeong et al. 2011). The specific capacitance of the CGA electrode was calculated from the CV curve at different scan rates as shown in Fig. 5c. The specific capacitance of CGA was $125.22 \mathrm{~F} / \mathrm{g}, 122.71 \mathrm{~F} / \mathrm{g}$, $118.08 \mathrm{~F} / \mathrm{g}, 110.54 \mathrm{~F} / \mathrm{g}$, and $101.78 \mathrm{~F} / \mathrm{g}$ when the scanning rates were $5 \mathrm{mV} / \mathrm{s}, 10 \mathrm{mV} / \mathrm{s}$, $20 \mathrm{mV} / \mathrm{s}, 50 \mathrm{mV} / \mathrm{s}$, and $100 \mathrm{mV} / \mathrm{s}$, respectively. As the scan rate was increased from 5 $\mathrm{mV} / \mathrm{s}$ to $100 \mathrm{mV} / \mathrm{s}$, the specific capacitance was only reduced $23.44 \mathrm{~F} / \mathrm{g}$, and the capacitance retention rate was as high as $81.28 \%$. The excellent cycle stability of the supercapacitors can play an important role in practical applications. Figure $5 d$ shows the capacitance retention of the CGA electrode after 5000 cycles of continuous charging and discharging. The inset shows the GCD curve of the CGA electrode after 5000 cycles of continuous charging and discharging at a current density of $2 \mathrm{~A} / \mathrm{g}$. The GCD curve of the CGA electrode maintained the original isosceles triangle after 5000 cycles of charge and 
discharge, and the capacitance retention rate was $98.3 \%$, which indicated that the CGA electrode had excellent long-term electrochemical stability. Compared with other composite electrodes (Table 3.), the CGA electrode exhibited both high specific capacitance and good electrochemical stability.
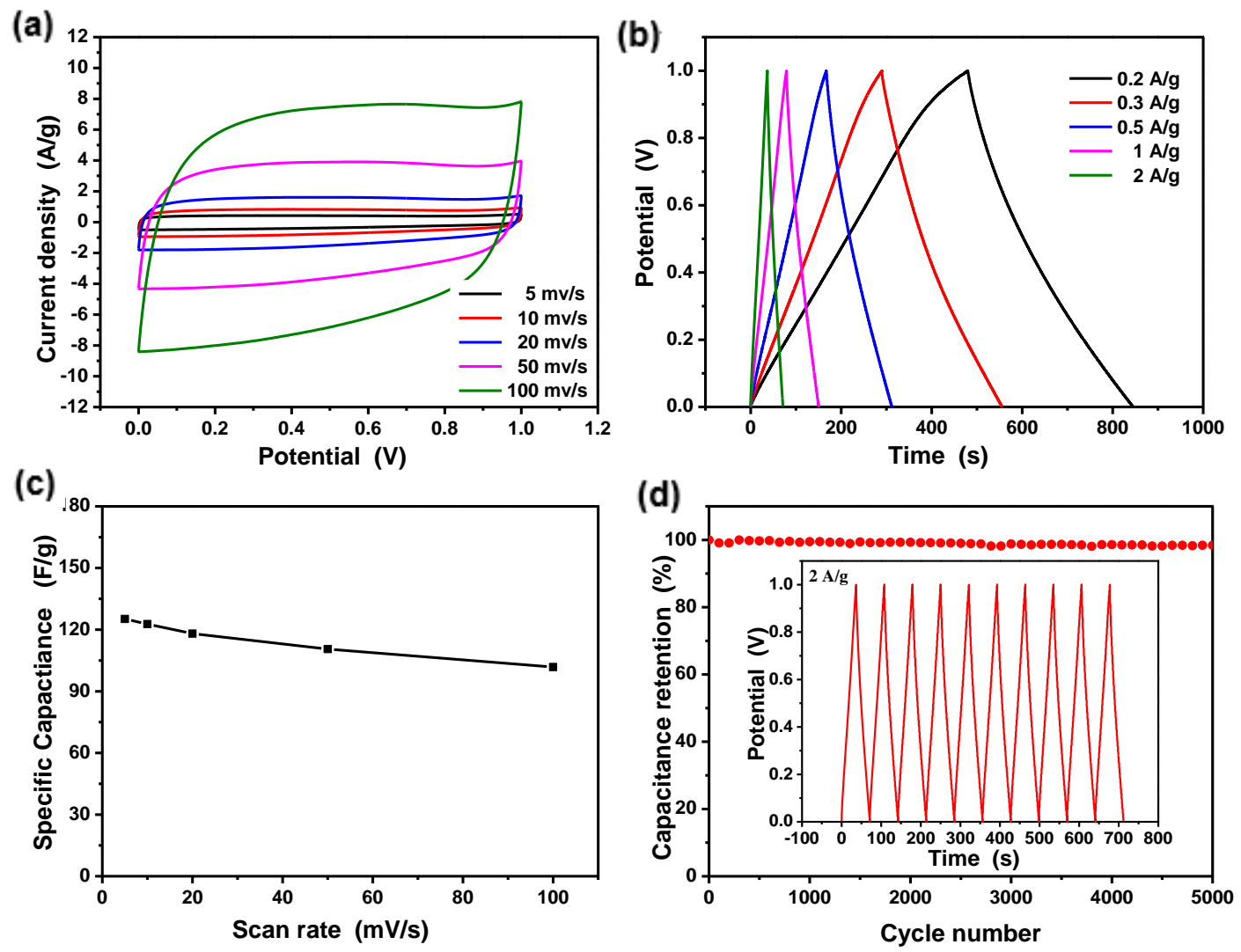

Fig. 5. (a) CV curves of CGA electrode at different scan rates, (b) GCD curves of CGA electrode at different current densities, (c) specific capacitances of CGA electrode at different scan rate, and (d) cycling performance of the CGA electrode at $2 \mathrm{~A} / \mathrm{g}$

Table 3. Specific capacitance of different composite electrodes

\begin{tabular}{|c|c|c|c|}
\hline Composite electrodes & Specific capacitances & Cycling Performance & References \\
\hline CGA & $125.5 \mathrm{~F} \cdot \mathrm{g}^{-1}, 5 \mathrm{mV} \cdot \mathrm{s}^{-1}$ & $98.3 \%, 5000 \mathrm{cycles}$ at $2 \mathrm{~A} \cdot \mathrm{g}^{-1}$ & This work \\
\hline Graphene/Cellulose & $120 \mathrm{~F} \cdot \mathrm{g}^{-1}, 1 \mathrm{mV} \cdot \mathrm{s}^{-1}$ & $99 \%, 5000 \mathrm{cycles}$ at $50 \mathrm{mV} \cdot \mathrm{s}^{-1}$ & $\begin{array}{c}\text { (Weng et al. } \\
2011)\end{array}$ \\
\hline 3D holey $\mathrm{MnO}_{2} / \mathrm{HGO}$ & $117.45 \mathrm{~F} \cdot \mathrm{g}^{-1}, 5 \mathrm{mV} \cdot \mathrm{s}^{-1}$ & $\mathrm{~N} / \mathrm{A}$ & $\begin{array}{c}\text { Wang et al. } \\
2015)\end{array}$ \\
\hline $\mathrm{rGO} / \mathrm{PPy}$ hybrid paper & $440 \mathrm{mF} \cdot \mathrm{cm}^{-1}, 0.5 \mathrm{~A} \cdot \mathrm{g}^{-1}$ & $81 \%, 1000 \mathrm{cycles}$ at $6 \mathrm{~A} \cdot \mathrm{g}^{-1}$ & $\begin{array}{c}\text { Shu et al. } \\
2016)\end{array}$ \\
\hline $\begin{array}{c}\mathrm{PANI} / \mathrm{BC} / \mathrm{Graphene} \\
\text { paper }\end{array}$ & $6.15 \mathrm{~F} \cdot \mathrm{cm}^{-1}, 1 \mathrm{~mA} \cdot \mathrm{cm}^{-2}$ & $56.3 \%, 8000 \mathrm{cycles}$ at 50 & $\begin{array}{c}\text { (Liu et al. } \\
2016)\end{array}$ \\
\hline $\mathrm{RGO} / \mathrm{PPy} / \mathrm{CCFs}$ & $122.7 \mathrm{~F} \cdot \mathrm{g}^{-1}, 20 \mathrm{mV} \cdot \mathrm{s}^{-1}$ & $84 \%, 600 \mathrm{cycles}$ at $20 \mathrm{mV} \cdot \mathrm{s}^{-1}$ & $\begin{array}{c}(\text { Lyu et al. } \\
2016)\end{array}$ \\
\hline
\end{tabular}




\section{CONCLUSIONS}

1. Graphene oxide (GO) and cellulose nanofibers (CNF) were used as starting materials, and low-cost CGA electrodes were successfully prepared by simple hydrothermal method and hydrothermal process optimization. The porous structure of the CGA electrode provided more effective delivery routes for ions during charge and discharge.

2. The specific surface area and maximum pore diameter of the CGA electrode were $17.71 \mathrm{~m}^{2} / \mathrm{g}$ and $3.61 \mathrm{~nm}$, respectively. The CGA electrode used CNF as the carrier, and the cross-linking with GO increased the specific surface area of the aerogel, which could be better used as an electrolyte reservoir.

3. The symmetric capacitor assembled from the CGA electrode exhibited excellent double-layer capacitance performance with a high specific capacitance of $125.5 \mathrm{~F} / \mathrm{g}$ at the scan rate of $5 \mathrm{mV} / \mathrm{s}$. The specific capacitance retention of the CGA electrode was $98.3 \%$ after 5000 cycles.

\section{ACKNOWLEDGMENTS}

The authors completed this work with financial support from the National Key R\&D Program of China (Grant No. 2017YFD0600804).

\section{REFERENCES CITED}

Chen, W., Yu, H., Lee, S.-Y., Wei, T., Li, J., and Fan, Z. (2018). "Nanocellulose: A promising nanomaterial for advanced electrochemical energy storage," Chem. Soc. Rev. 47(8), 2837-2872. DOI: 10.1039/C7CS00790F

Chen, W., Yu, H., and Liu, Y. (2011). "Preparation of millimeter-long cellulose I nanofibers with diameters of 30-80 nm from bamboo fibers," Carbohyd. Polym. 86(2), 453-461. DOI: 10.1016/j.carbpol.2011.04.061

Du, W., Qi, S., Zhou, B., Sun, P., Zhu, L., and Jiang, X. (2014). "A surfactant-free waterprocessable all-carbon composite and its application to supercapacitor," Electrochim. Acta 146, 353-358. DOI: 10.1016/j.electacta.2014.09.030

Du, X., Zhang, Z., Liu, W., and Deng, Y. (2017). "Nanocellulose-based conductive materials and their emerging applications in energy devices - A review," Nano Energy 35, 299-320. DOI: 10.1016/j.nanoen.2017.04.001

Dufresne, A. (2013). "Nanocellulose: A new ageless bionanomaterial," Mater. Today 16(6), 220-227. DOI: 10.1016/j.mattod.2013.06.004

Feng, Y., Zhang, X., Shen, Y., Yoshino, K., and Feng, W. (2012). "A mechanically strong, flexible and conductive film based on bacterial cellulose/graphene nanocomposite," Carbohyd. Polym. 87(1), 644-649. DOI:

10.1016/j.carbpol.2011.08.039 
Gao, K., Shao, Z., Wu, X., Wang, X., Li, J., Zhang, Y., Wang, W., and Wang, F. (2013). "Cellulose nanofibers/reduced graphene oxide flexible transparent conductive paper," Carbohyd. Polym. 97(1), 243-251. DOI: 10.1016/j.carbpol.2013.03.067

González, A., Goikolea, E., Barrena, J.A., and Mysyk, R. (2016). "Review on supercapacitors: Technologies and materials," Renew. Sust. Energ. Rev. 58, 11891206. DOI: 10.1016/j.rser.2015.12.249

Gryglewicz, G., Śliwak, A., and Béguin, F. (2013). "Carbon nanofibers grafted on activated carbon as an electrode in high-power supercapacitors," ChemSusChem 6(8), 1516-1522. DOI: 10.1002/cssc.201300095

Hao, P., Zhao, Z., Leng, Y., Tian, J., Sang, Y., Boughton, R.I., Wong, C., Liu, H., and Yang, B. (2015). "Graphene-based nitrogen self-doped hierarchical porous carbon aerogels derived from chitosan for high performance supercapacitors," Nano Energy 15, 9-23. DOI: 10.1016/j.nanoen.2015.02.035

Hummers Jr, W. S., and Offeman, R. E. (1958). "Preparation of graphitic oxide," J. Am. Chem. Soc. 80(6), 1339-1339. DOI: 10.1021/ja01539a017

Isogai, A., Saito, T., and Fukuzumi, H. (2011). "TEMPO-oxidized cellulose nanofibers," Nanoscale 3(1), 71-85. DOI: 10.1039/c0nr00583e

Izadi-Najafabadi, A., Yasuda, S., Kobashi, K., Yamada, T., Futaba, D.N., Hatori, H., Yumura, M., Iijima, S., and Hata, K. (2010). "Extracting the full potential of singlewalled carbon nanotubes as durable supercapacitor electrodes operable at $4 \mathrm{~V}$ with high power and energy density," Adv. Mater. 22(35), E235-E241. DOI: 10.1002/adma.200904349

Jeong, H. M., Lee, J. W., Shin, W. H., Choi, Y. J., Shin, H. J., Kang, J. K., and Choi, J. W. (2011). "Nitrogen-doped graphene for high-performance ultracapacitors and the importance of nitrogen-doped sites at basal planes," Nano Lett. 11(6), 2472-2477. DOI: $10.1021 / \mathrm{nl} 2009058$

Lei, Z., Zhang, J., Zhang, L. L., Kumar, N. A., and Zhao, X. (2016). "Functionalization of chemically derived graphene for improving its electrocapacitive energy storage properties," Energ. Environ. Sci. 9(6), 1891-1930. DOI: 10.1039/c6ee00158k

Li, Z., Liu, J., Jiang, K., and Thundat, T. (2016). "Carbonized nanocellulose sustainably boosts the performance of activated carbon in ionic liquid supercapacitors," Nano Energy 25, 161-169. DOI: 10.1016/j.nanoen.2016.04.036

Liu, R., Ma, L., Huang, S., Mei, J., Xu, J., and Yuan, G. (2016). "Large areal mass, flexible and freestanding polyaniline/bacterial cellulose/graphene film for highperformance supercapacitors," RSC Adv. 6(109), 107426-107432. DOI: 10.1039/C6RA21920A

Lyu, S., Chang, H., Fu, F., Hu, L., Huang, J., and Wang, S. (2016). "Cellulose-coupled graphene/polypyrrole composite electrodes containing conducting networks built by carbon fibers as wearable supercapacitors with excellent foldability and tailorability," J Power Sources 327, 438-446. DOI: 10.1016/j.jpowsour.2016.07.091

Merlet, C., Rotenberg, B., Madden, P.A., Taberna, P.-L., Simon, P., Gogotsi, Y., and Salanne, M. (2012). "On the molecular origin of supercapacitance in nanoporous carbon electrodes," Nat. Mater. 11(4), 306. DOI: 10.1038/nmat3260

Okita, Y., Saito, T., and Isogai, A. (2010). "Entire surface oxidation of various cellulose microfibrils by TEMPO-mediated oxidation," Biomacromolecules 11(6), 1696-1700. DOI: $10.1021 / \mathrm{bm} 100214 \mathrm{~b}$ 
Park, M., Lee, D., Shin, S., Kim, H.J., and Hyun, J. (2016). "Flexible conductive nanocellulose combined with silicon nanoparticles and polyaniline," Carbohydr Polym. 140, 43-50. DOI: 10.1016/j.carbpol.2015.12.046

Saeed, G., Kumar, S., Kim, N. H., and Lee, J. H. (2018). "Fabrication of 3D graphene$\mathrm{CNTs} / \alpha-\mathrm{MoO} 3$ hybrid film as an advance electrode material for asymmetric supercapacitor with excellent energy density and cycling life," Chem. Eng. J. 352, 268-276. DOI: 10.1016/j.cej.2018.07.026

Saito, T., Nishiyama, Y., Putaux, J.-L., Vignon, M., and Isogai, A. (2006).

"Homogeneous suspensions of individualized microfibrils from TEMPO-catalyzed oxidation of native cellulose," Biomacromolecules 7(6), 1687-1691. DOI: $10.1021 / \mathrm{bm} 060154 \mathrm{~s}$

Shu, K., Wang, C., Zhao, C., Ge, Y., and Wallace, G.G. (2016). "A free-standing graphene-polypyrrole hybrid paper via electropolymerization with an enhanced areal capacitance," Electrochim Acta 212, 561-571. DOI: 10.1016/j.electacta.2016.07.052

Sui, Z.-Y., Meng, Y.-N., Xiao, P.-W., Zhao, Z.-Q., Wei, Z.-X., and Han, B.-H. (2015). "Nitrogen-doped graphene aerogels as efficient supercapacitor electrodes and gas adsorbents," ACS Appl. Mater. Inter. 7(3), 1431-1438. DOI: 10.1021/am5042065

Suktha, P., Chiochan, P., Iamprasertkun, P., Wutthiprom, J., Phattharasupakun, N., Suksomboon, M., Kaewsongpol, T., Sirisinudomkit, P., Pettong, T., and Sawangphruk, M. (2015). "High-performance supercapacitor of functionalized carbon fiber paper with high surface ionic and bulk electronic conductivity: Effect of organic functional groups," Electrochim. Acta 176, 504-513. DOI: 10.1016/j.electacta.2015.07.044

Sun, G., Li, K., Xie, L., Wang, J., and Li, Y. (2012). "Preparation of mesoporous carbon spheres with a bimodal pore size distribution and its application for electrochemical double layer capacitors based on ionic liquid as the electrolyte," Micropor. Mesopor. Mater. 151, 282-286. DOI: 10.1016/j.micromeso.2011.10.023

Titirici, M.-M., White, R. J., Falco, C., and Sevilla, M. (2012). "Black perspectives for a green future: Hydrothermal carbons for environment protection and energy storage," Energ. Environ. Sci. 5(5), 6796-6822. DOI: 10.1039/C2EE21166A

Wang, H., Bian, L., Zhou, P., Tang, J., and Tang, W. (2013). "Core-sheath structured bacterial cellulose/polypyrrole nanocomposites with excellent conductivity as supercapacitors," J. Mater. Chem. A 1(3), 578-584. DOI: 10.1039/C2TA00040G

Wang, L., Deng, D., Salley, S. O., and Ng, K. S. (2015). "Facile synthesis of 3-D composites of $\mathrm{MnO}_{2}$ nanorods and holey graphene oxide for supercapacitors," $J$. Mater. Sci. 50(19), 6313-6320. DOI: 10.1007/s10853-015-9169-8

Wen, J., Li, S., Zhou, K., Song, Z., Li, B., Chen, Z., Chen, T., Guo, Y., and Fang, G. (2016). "Flexible coaxial-type fiber solid-state asymmetrical supercapacitor based on $\mathrm{Ni}_{3} \mathrm{~S}_{2}$ nanorod array and pen ink electrodes," J. Power Sources 324, 325-333. DOI: 10.1016/j.jpowsour.2016.05.087

Weng, Z., Su, Y., Wang, D. W., Li, F., Du, J., and Cheng, H. M. (2011). "Graphenecellulose paper flexible supercapacitors," Adv Energy Mater 1(5), 917-922. DOI:org/10.1002/aenm.201100312

Wu, X., Tang, J., Duan, Y., Yu, A., Berry, R. M., and Tam, K. C. (2014). "Conductive cellulose nanocrystals with high cycling stability for supercapacitor applications," $J$. Mater. Chem. A 2(45), 19268-19274. DOI: 10.1039/C4TA04929B

Xu, Y., Chen, C.-Y., Zhao, Z., Lin, Z., Lee, C., Xu, X., Wang, C., Huang, Y., Shakir, M. I., and Duan, X. (2015). "Solution processable holey graphene oxide and its derived 
macrostructures for high-performance supercapacitors," Nano Lett. 15(7), 46054610. DOI: $10.1021 /$ acs.nanolett.5b01212

Yan, J., Wang, Q., Wei, T., Jiang, L., Zhang, M., Jing, X., and Fan, Z. (2014). "Templateassisted low temperature synthesis of functionalized graphene for ultrahigh volumetric performance supercapacitors," ACS Nano 8(5), 4720-4729. DOI: $10.1021 / \mathrm{nn} 500497 \mathrm{k}$

Yu, S., Li, Y., and Pan, N. (2014). "KOH activated carbon/graphene nanosheets composites as high performance electrode materials in supercapacitors," RSC Adv. 4(90), 48758-48764. DOI: 10.1039/c4ra06710j

Zhang, H., Dou, C., Pal, L., and Hubbe, M. A. (2019). "Review of electrically conductive composites and films containing cellulosic fibers or nanocellulose," BioResources 14(3), 7494-7542.

Zhou, T., Chen, D., Jiu, J., Nge, T.T., Sugahara, T., Nagao, S., Koga, H., Nogi, M., Suganuma, K., Wang, X., Liu, X., Cheng, P., Wang, T., and Xiong, D. (2013). "Electrically conductive bacterial cellulose composite membranes produced by the incorporation of graphite nanoplatelets in pristine bacterial cellulose membranes," Express Polym Lett 7(9), 756-766. DOI: 10.3144/expresspolymlett.2013.73

Zhu, Y., Murali, S., Stoller, M. D., Ganesh, K., Cai, W., Ferreira, P. J., Pirkle, A., Wallace, R. M., Cychosz, K. A., and Thommes, M. (2011). "Carbon-based supercapacitors produced by activation of graphene," Science 332(6037), 15371541. DOI: $10.1126 /$ science. 1200770

Article submitted: September 12, 2019; Peer review completed: November 17, 2019; Revised version received and accepted: November 24, 2019; Published: December 4, 2019.

DOI: 10.15376/biores.15.1.677-690 